\title{
ANÁLISE DA INFLUÊNCIA DO ÂNGULO DE AFIAÇÃO DO ELETRODO DE TUNGSTÊNIO NA PENETRAÇÃO DO CORDÃO DE SOLDA NO PROCESSO TIG
}

\author{
ANALYSIS OF THE INFLUENCE OF THE TUNGSTEN ELECTRODE SHARPENING \\ ANGLE ON THE WELD BEAD PENETRATION IN THE TIG PROCESS
}

\author{
Diogo Yoshiaki Sunamoto ${ }^{\mathrm{I}}$ \\ Carlos Roberto Santos ${ }^{\text {II }}$ \\ Edmilson Antonio Sarni ${ }^{\mathrm{III}}$ \\ Maria Aparecida Bovério ${ }^{\mathrm{IV}}$ \\ Mírian Isabel Junqueira Sarni ${ }^{\mathrm{V}}$
}

\begin{abstract}
RESUMO
Este trabalho tem por finalidade analisar a interferência da afiação do eletrodo de tungstênio na penetração da solda, com uma execução autógena, do processo de soldagem TIG, sob superfície. A variável analisada foi o ângulo de afiação do eletrodo não consumível, no qual foram realizadas três afiações com ângulos de $15^{\circ}, 30^{\circ} \mathrm{e} 45^{\circ} \mathrm{e}$, posteriormente, feita a medição da penetração. Determinou-se tal dimensão por meio de análise metalográfica e do programa Image J. Os procedimentos experimentais mostraram que a penetração foi diretamente influenciada pela variável em questão, pois nenhum outro parâmetro do processo (corrente, vazão de gás, velocidade de soldagem, altura do eletrodo, ângulo da tocha) foram alterados, donde concluiu-se que o ângulo de afiação do eletrodo altera a penetração da solda no processo TIG.
\end{abstract}

Palavras-chave: Penetração do Cordão. Afiação. Soldagem TIG.

\begin{abstract}
The purpose of this work is to analyze the interference of the tungsten electrode sharpness in the penetration of the weld, with an autogenous execution of the TIG welding process under surface. The analyzed variable was the sharpening angle of the non-consumable electrode, in which three indentations with angles of $15^{\circ}, 30^{\circ}$ and $45^{\circ}$ were made and then the penetration measurement was performed. The experimental procedures showed that the penetration was directly influenced by the variable in question, since no other parameter of the process (current, gas flow, welding speed, weld height, electrode, torch angle) were changed, where it was
\end{abstract}

\footnotetext{
${ }^{\text {I }}$ Estudante do Curso Superior de Tecnologia em Mecânica: Processos de Soldagem da Faculdade de Tecnologia (FATEC) de Sertãozinho - São Paulo - Brasil. E-mail: diogoyoshiaki@ gmail.com

${ }^{\text {II }}$ Estudante do Curso Superior de Tecnologia em Mecânica: Processos de Soldagem da Faculdade de Tecnologia (FATEC) de Sertãozinho - São Paulo - Brasil. E-mail: carlosrobertosantos24@ gmail.com

IIIProf. Me. da Faculdade de Tecnologia (FATEC) de Sertãozinho - São Paulo - Brasil. E-mail: edmilsonsarni@hotmail.com

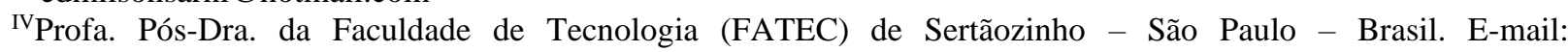
mariaboverio@hotmail.com

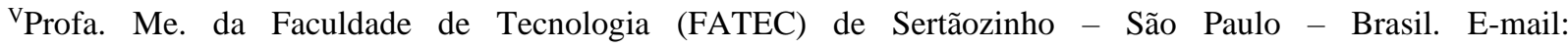
miriansarni@hotmail.com
} 


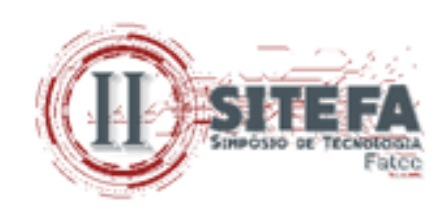

concluded that the sharpening angle of the electrode changes the penetration of the weld in the TIG process.

Keywords: Penetration of the Cord. Sharpening. TIG Welding.

Data de submissão do artigo: 27/06/2019.

Data de aprovação do artigo: 23/07/2019.

DOI:

\section{INTRODUÇÃO}

De acordo com Modenesi (2013) "o processo de soldagem a arco TIG (ou GTAW) é muito usado na soldagem de materiais mais sofisticados, incluindo aços inoxidáveis e ligas de metais reativos, e quando um bom acabamento e uma elevada qualidade das soldas são requeridos".

Entretanto, o processo de soldagem TIG manual apresenta limitações em sua utilização, principalmente com relação à espessura soldável, devido à sua baixa taxa de deposição em relação a outros processos de soldagem a arco com eletrodo consumível. Estas características limitam a utilização desse processo para soldagem de peças de pequena espessura, soldagem de passe de raiz ou para casos especiais em que as propriedades do material usado ou as necessidades da aplicação justifiquem o seu uso em juntas de elevada espessura. Assim, a possibilidade de manipular a penetração do cordão de solda, particularmente aumentando o seu valor em mais de $100 \%$, por mudanças relativamente simples no processo podem, potencialmente, aumentar a aplicação da soldagem TIG de forma expressiva (MODENESI, 2013).

As fontes para a soldagem TIG são, do ponto de vista construtivo e operacional, semelhantes às fontes utilizadas para soldagem com eletrodos revestidos, porém, em geral apresentam possibilidade de ajuste de corrente mais preciso e menores valores de corrente mínima de operação (MARQUES; MODENESI; BRACARENSE, 2009).

Uma das variáveis que podem influenciar na penetração do cordão é o ângulo de afiação da ponta do eletrodo de tungstênio. Essa preparação é feita por meio de esmerilhamento da ponta, sempre no sentido longitudinal, para facilitar o direcionamento dos elétrons. A norma prática recomenda que o comprimento da afiação seja duas vezes o diâmetro do eletrodo, para soldagem em corrente contínua. Essa regra gera um ângulo no cone de afiação de aproximadamente $30^{\circ}$ (SERVIÇO NACIONAL DE APRENDIZAGEM INDUSTRIAL, 2013).

O objetivo deste trabalho é analisar a variação que o cordão de solda apresenta utilizando diferentes ângulos de afiação e determinar sua influência na penetração do cordão, determinando o ângulo que produz a maior penetração.

\section{PROCESSO DE SOLDAGEM GTAW}

O processo Tungsten Inert Gás (TIG) - também é conhecido como Gás Tungsten Arc Welding $(G T A W)$ - consiste no aquecimento obtido através de um arco elétrico gerado com o auxílio de um eletrodo não consumível de tungstênio, que não deve se fundir para evitar defeitos ou descontinuidades no cordão da solda. O eletrodo e a poça de fusão são protegidos por uma atmosfera gasosa constituída de gás inerte, ou seja, um gás que não reage com outros materiais, 
por exemplo, argônio e hélio (SERVIÇO NACIONAL DE APRENDIZAGEM INDUSTRIAL, 2013).

O processo de soldagem GTAW é amplamente utilizado na soldagem de aços carbono e inoxidável de menor espessura ou em passes de raiz em tubulações. Normalmente esse processo é feito com corrente contínua, eletrodo negativo e proteção de argônio, hélio ou a mistura desses dois gases (MODENESI, 2011).

Dentre as características do processo TIG, cita-se a possibilidade de utilizar material de adição ou realizar a soldagem fundindo apenas os materiais de base (solda autógena). Além disso, a fonte de corrente elétrica é do tipo constante, com valor de saída ajustável de acordo com cada operação e pode ser contínua, alternada ou pulsada. No que diz respeito a operação, normalmente, é manual e pode ser feita em qualquer posição. Por outro lado, a mecanização do processo é comum e de fácil implementação, desde que usados dispositivos auxiliares de soldagem adequados (MARQUES; MODENESI; BRACARENSE, 2009).

\subsection{Ensaios macrográficos}

De acordo com Pavanati (2019), o procedimento de preparação de uma amostra para análise microestrutural é denominado como Metalografia, que consiste no estudo e interpretação da estrutura interna dos materiais a partir de uma superfície preparada, e a relação dessas estruturas com as suas composições químicas, propriedades físicas e mecânicas

De acordo com Colpaert (1983), a macrografia consiste em examinar o aspecto de uma peça ou amostra metálica a partir de uma secção plana devidamente polida e atacada por reativo apropriado por meio de vista desarmada ou com o auxílio de uma lupa. O aspecto obtido denominado de macroestrutura, pode ser reproduzido a partir de documentos em tamanho natural ou com ampliação 10 vezes maior. Em caso de ampliações maiores, emprega-se o termo micrografia, pois são obtidos através de microscópios.

Em outras palavras, o ensaio macrográfico consiste na verificação realizada a olho nu ou com ampliação de no máximo 10 vezes, de uma superfície plana e preparada adequadamente por meio de lixamento, que é normalmente atacada por uma substância que reage com ela e revela detalhes macrográficos da estrutura do material ou da junta de solda ensaiada. O termo macrografia, além de determinar o tipo de ensaio realizado, abrange os documentos gerados a partir deste, tais como fotografia e impressões (SERVIÇO NACIONAL DE APRENDIZAGEM INDUSTRIAL, 2013).

\section{PROCEDIMENTOS METODOLÓGICOS}

Para realização deste estudo utilizou-se a pesquisa bibliográfica, definida por Gil (2002, p. 44) como o tipo de pesquisa que é "desenvolvida com base em material já elaborado, constituído principalmente de livros e artigos científicos" e a pesquisa experimental que "consiste em determinar um objeto de estudo, selecionar as variáveis que seriam capazes de influenciá-lo, definir as formas de controle e de observação dos efeitos que a variável produz no objeto (GIL, 2002, p. 47). A etapa de preparação do corpo de prova e soldagem foi realizada no laboratório de soldagem do SENAI Sertãozinho, já a preparação das amostras para ataque e a macrografia foram realizadas na FATEC Sertãozinho, no laboratório de análises metalográficas. 


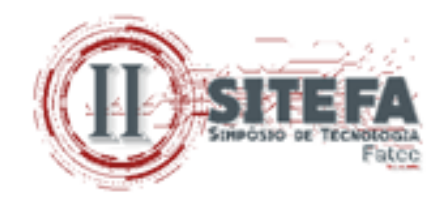

\subsection{Materiais}

Para realização do experimento de solda, utilizou-se uma fonte de soldagem inversora, modelo Thermal Arc 300AC/DC. Os passes foram realizados em corrente contínua polaridade direta. A execução do processo foi mecanizada, em que a tocha de soldagem foi acoplada ao posicionador de soldagem, local em que também foi acoplado o corpo de prova, conforme apresentado na fotografia 1 . O material utilizado na fabricação do corpo de prova foi o tubo de aço carbono SAE 1020 de quatro polegadas de diâmetro.

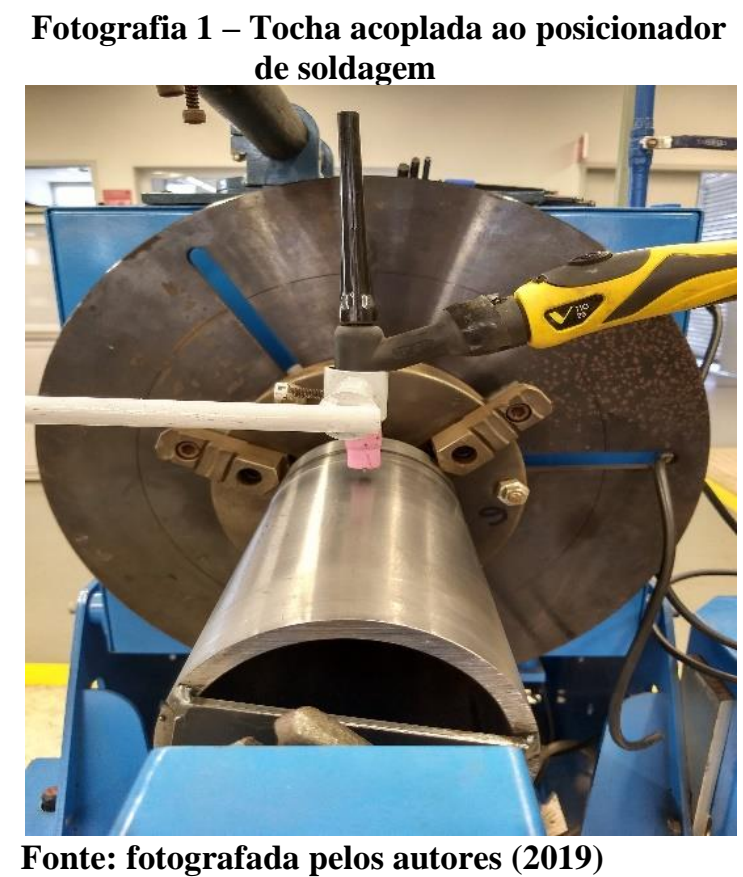

\subsubsection{Preparação do corpo de prova}

O corpo de prova foi cortado com comprimento de $250 \mathrm{~mm}$, sua superfície foi usinada para remoção de óxidos e limpa com solvente para livrá-la de qualquer resíduo de contaminantes oriundos do processo.

\subsubsection{Eletrodo}

Foi utilizado eletrodo de tungstênio com adição de $2 \%$ de óxido de lantânio, classificado como AWS EWLa - 2, ponta azul, com diâmetro de 2,4mm. Os eletrodos foram afiados numa Afiadora de Tungstênio em três ângulos distintos, conforme fotografias 2,3 e 4. 


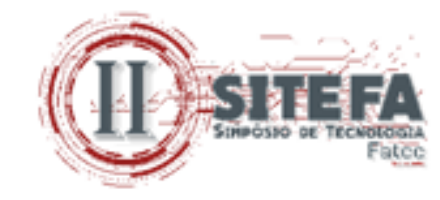

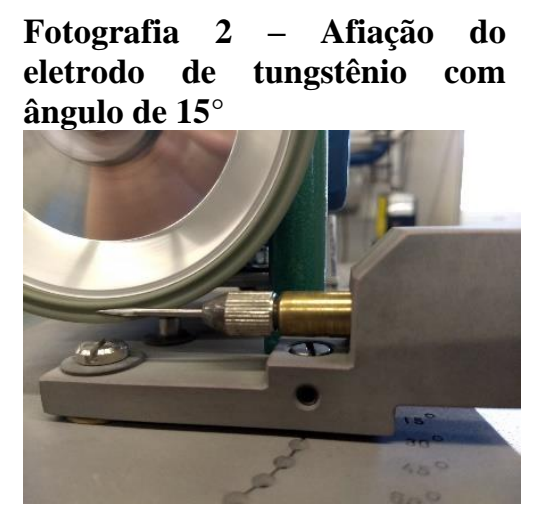

Fonte: fotografada pelos autores (2019)

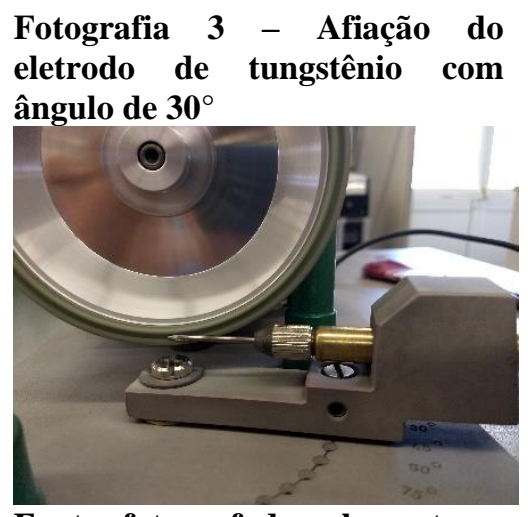

Fonte: fotografada pelos autores (2019)
Fotografia 4 - Afiação do eletrodo de tungstênio com ângulo de $\mathbf{4 5}^{\circ}$

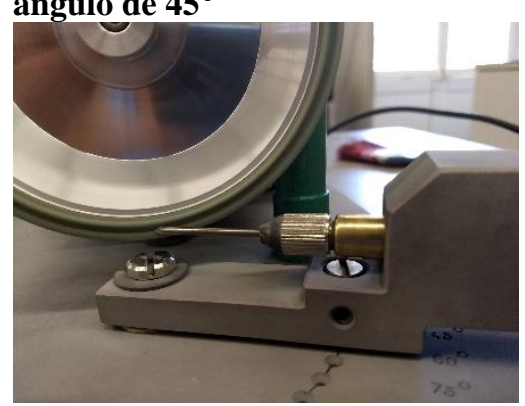

Fonte: fotografada pelos autores (2019)

\subsubsection{Gás de Proteção}

O gás de proteção utilizado foi Argônio Puro fornecido pela empresa White Martins.

\subsection{Métodos e técnicas}

Os experimentos foram realizados utilizando a técnica de soldagem autógena, sobre a superfície do tubo, onde a tocha foi posicionada em um ângulo de $90^{\circ}$ em relação ao eixo central do tubo, conforme Fotografia 1. Foram realizados nove passes na superfície do corpo de prova com três ângulos de afiação diferentes nos eletrodos. Para cada grupo de três passes utilizou-se um valor de corrente, com intuito de observar a variação da penetração em função do ângulo de afiação, em diferentes faixas de corrente. O comprimento do eletrodo para fora do bocal foi controlado com a combinação de dois paquímetros, sendo um o Paquímetro Universal e o outro o Paquímetro de Profundidade, conforme Fotografias 5, 6 e 7. A distância entre o eletrodo e a peça foi padronizada com o diâmetro do eletrodo de tungstênio de $2,4 \mathrm{~mm}$, conforme Fotografia 8. Para garantir que a temperatura do corpo de prova não influenciasse na penetração, a partir do segundo cordão, aguardou-se o resfriamento da peça entre cada solda. Os parâmetros utilizados na soldagem encontram-se no Quadro 1.

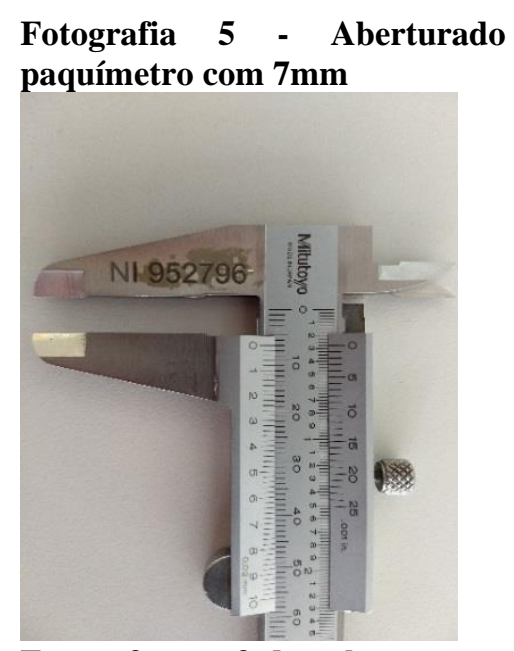

Fonte: fotografada pelos autores (2019)
Fotografia 6 - Calibração do paquímetro de profundidade

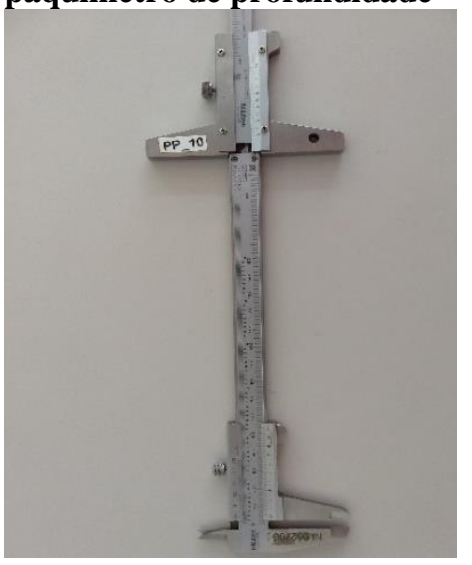

Fonte: fotografada pelos autores (2019)
Fotografia 7 - Regulagem do comprimento externo de $7 \mathrm{~mm}$

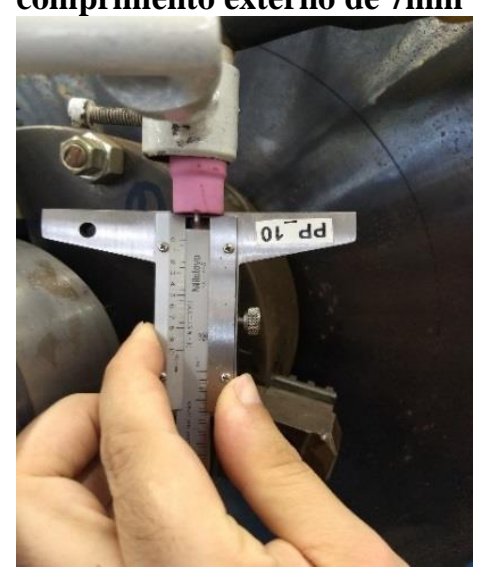

Fonte: fotografada pelos autores (2019) 

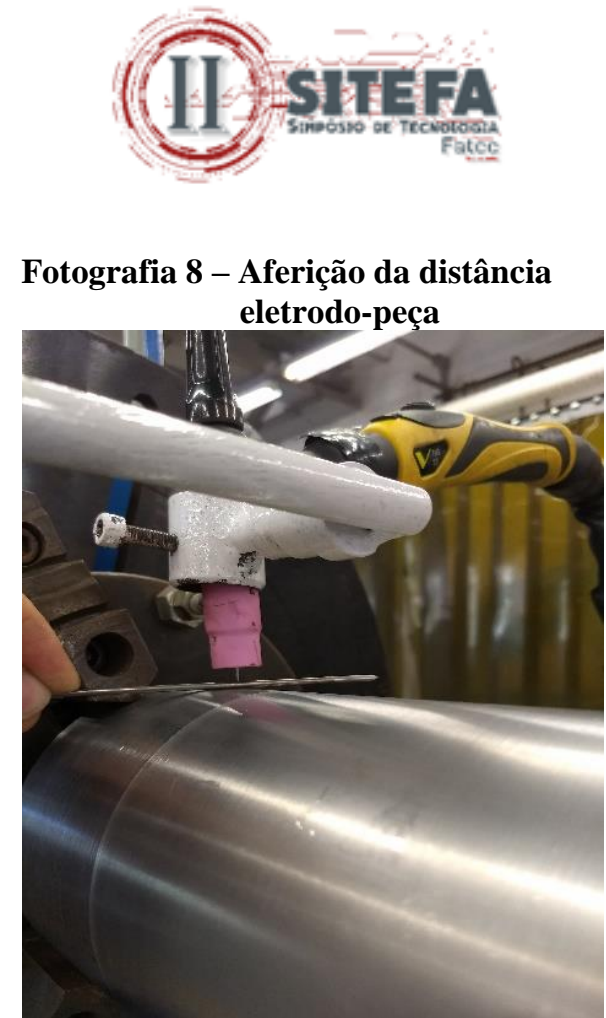

Fonte: fotografada pelos autores (2019)

Quadro 1 - Parâmetros Utilizados na Soldagem do Corpo de Prova

\begin{tabular}{|c|c|c|c|c|c|c|}
\hline $\begin{array}{c}\text { Corpo de } \\
\text { prova }\end{array}$ & $\begin{array}{c}\text { Ângulo de } \\
\text { afiação do } \\
\text { eletrodo }\end{array}$ & $\begin{array}{l}\text { Stick } \\
- \text { out } \\
\text { (mm) }\end{array}$ & $\begin{array}{c}\text { Altura } \\
\text { eletrodo } \\
\text { peça } \\
(\mathbf{m m})\end{array}$ & $\begin{array}{l}\text { Corrente } \\
\text { (A) }\end{array}$ & $\begin{array}{c}\text { Velocidade } \\
\text { de soldagem } \\
(\mathrm{mm} / \mathrm{s})\end{array}$ & $\begin{array}{l}\text { Vazão de gás } \\
\text { (litros/min.) }\end{array}$ \\
\hline $\begin{array}{c}1^{\circ} \\
\text { CORDÃO }\end{array}$ & $15^{\circ}$ & 7 & 2,4 & \multirow{3}{*}{100} & 2,4 & 10 \\
\hline $\begin{array}{c}2^{\mathbf{o}} \\
\text { CORDÃO }\end{array}$ & $30^{\circ}$ & 7 & 2,4 & & 2,4 & 10 \\
\hline $\begin{array}{c}3^{\circ} \\
\text { CORDÃO }\end{array}$ & $45^{\circ}$ & 7 & 2,4 & & 2,4 & 10 \\
\hline $\begin{array}{c}4^{\circ} \\
\text { CORDÃO }\end{array}$ & $15^{\circ}$ & 7 & 2,4 & \multirow{3}{*}{120} & 2,4 & 10 \\
\hline $\begin{array}{c}5^{\circ} \\
\text { CORDÃO }\end{array}$ & $30^{\circ}$ & 7 & 2,4 & & 2,4 & 10 \\
\hline $\begin{array}{c}6^{\mathbf{0}} \\
\text { CORDÃO }\end{array}$ & $45^{\circ}$ & 7 & 2,4 & & 2,4 & 10 \\
\hline $\begin{array}{c}7^{\circ} \\
\text { CORDÃO }\end{array}$ & $15^{\circ}$ & 7 & 2,4 & \multirow{3}{*}{160} & 2,4 & 10 \\
\hline $\begin{array}{c}\mathbf{8}^{\mathbf{0}} \\
\text { CORDÃO }\end{array}$ & $30^{\circ}$ & 7 & 2,4 & & 2,4 & 10 \\
\hline $\begin{array}{c}9^{\circ} \\
\text { CORDÃO }\end{array}$ & $45^{\circ}$ & 7 & 2,4 & & 2,4 & 10 \\
\hline
\end{tabular}

Fonte: elaborado pelos autores (2019) 


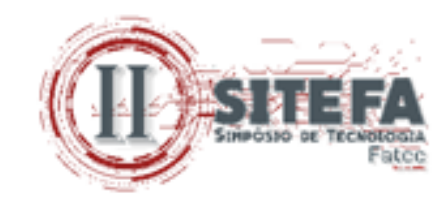

Foram utilizados três valores de corrente (100A, 120A e 160A) e, para cada valor, foram realizados três passes de solda variando o ângulo de afiação da ponta do eletrodo. A Fotografia 9 mostra o corpo de prova soldado.

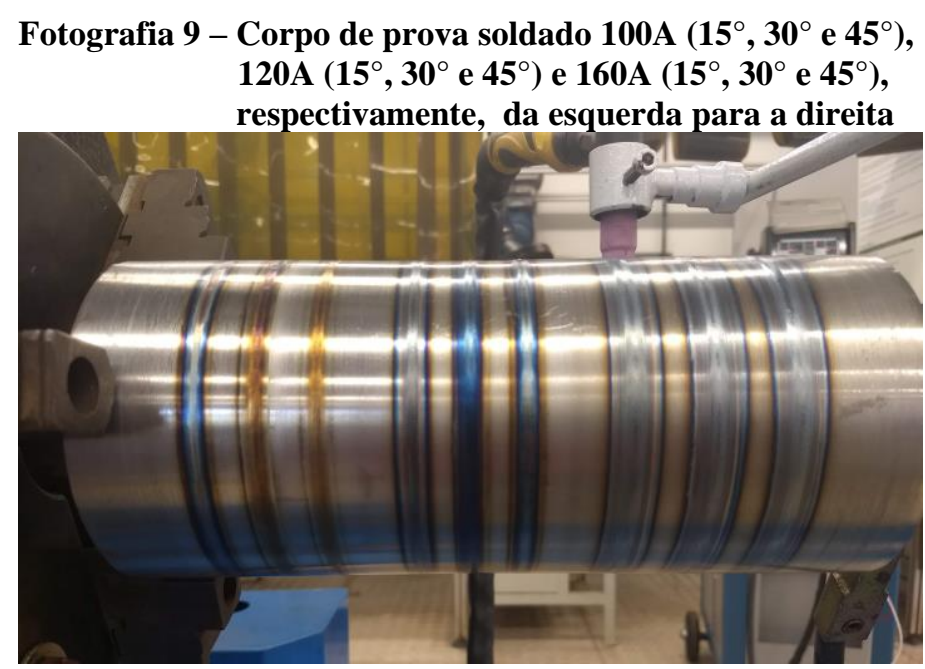

Fonte: fotografado pelos autores (2019)

\subsubsection{Preparação das amostras}

Os corpos de prova foram cortados em uma serra de fita horizontal Romarfra modelo RMF.200-E com refrigeração. O início e final dos passes de solda foram descartados. O restante foi cortado transversalmente em duas seções, conforme Fotografia 10. Em seguida, as peças foram lixadas gradualmente utilizando lixas de granulometria 100 até 600 mesh, até apresentarem superfície lisa, livre de riscos e uniforme. As peças foram atacadas quimicamente com nital 5\%, para revelar as diferentes regiões formadas durante a soldagem e possibilitar a análise macroestrutural da região soldada.

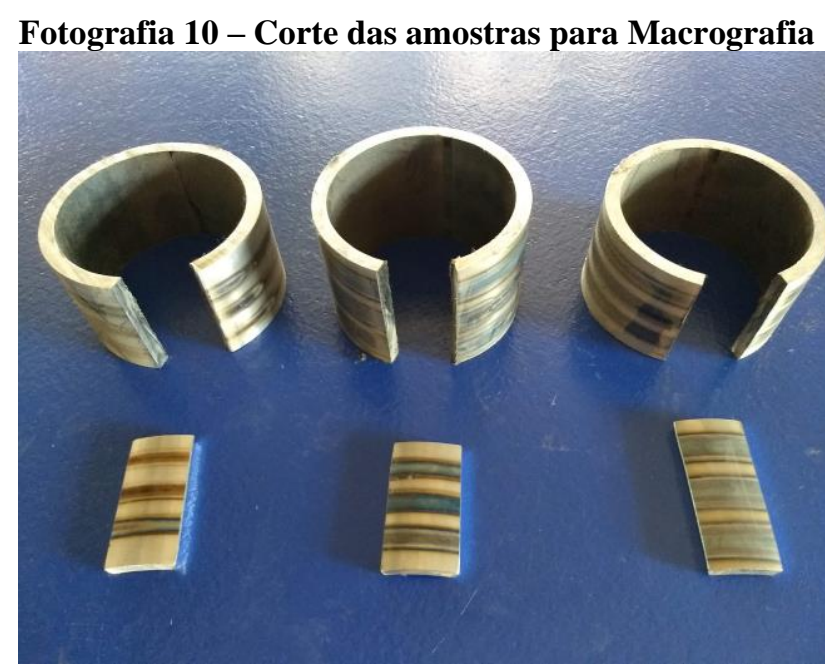

Fonte: fotografado pelos autores (2019) 


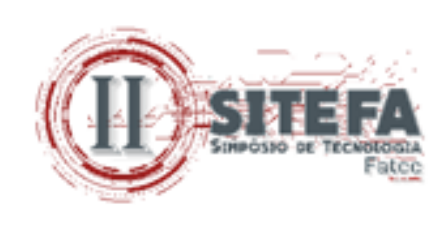

As macrografias da seção transversal dos corpos de prova foram obtidas através de câmera digital. As imagens foram analisadas através do programa IMAGE J, que permite realizar medições de áreas selecionadas em imagens, sendo necessário realizar calibração de uma distância conhecida, em função da imagem. Como base para calibração, foi utilizada a espessura da amostra.

A característica geométrica avaliada foi a penetração do passe de solda, através do perfil da junta atacada, conforme observa-se nas Fotografias 11, 12 e 13.

\section{RESULTADOS E DISCUSSÃO}

Iniciou-se a análise da parte experimental através dos parâmetros coletados durante a realização dos passes de solda. As leituras da tensão do arco foram obtidas através de multímetro conectado diretamente aos terminais da fonte de soldagem, desconsiderando eventuais perdas pelo circuito de soldagem.

Os valores coletados para tensão do arco em função do ângulo do vértice do eletrodo encontram-se no Quadro 2. Observou-se que, conforme o ângulo de afiação do eletrodo fica mais agudo, ocorre um aumento no valor da tensão, conforme identificado nos valores obtidos para as correntes de 100 e 160 amperes. Apenas a corrente de 120 amperes não seguiu esse padrão, nota-se que o valor de tensão mais alto foi obtido na soldagem com eletrodo afiado à $30^{\circ}$.

Quadro 2 - Tensão do circuito de soldagem em função do ângulo de afiação do eletrodo

\begin{tabular}{|c|c|c|}
\hline Corrente (A) & Ângulo do vértice (⿳) & Tensão do arco (V) \\
\hline \multirow{3}{*}{100} & 15 & 10,95 \\
\cline { 2 - 3 } & 30 & 10,83 \\
\cline { 2 - 3 } & 45 & 10,55 \\
\hline \multirow{3}{*}{120} & 15 & 11,20 \\
\cline { 2 - 3 } & 30 & 11,32 \\
\cline { 2 - 3 } & 45 & 10,87 \\
\cline { 2 - 3 } & 15 & 12,34 \\
\cline { 2 - 3 } & 30 & 11,81 \\
\hline \multirow{3}{*}{160} & 45 & 11,42 \\
\hline
\end{tabular}

Fonte: elaborado pelos autores (2019)

\subsection{Profundidade de penetração do cordão}

Além da influência na tensão, o ângulo de afiação do eletrodo também afeta a penetração da solda. Após preparação e ataque químico, as amostras foram analisadas através do software ImageJ e os contornos dos perfis da penetração da solda foram dimensionados.

Conforme observa-se na Fotografia 11, a penetração aumenta conforme aumenta-se o ângulo de afiação do eletrodo. 


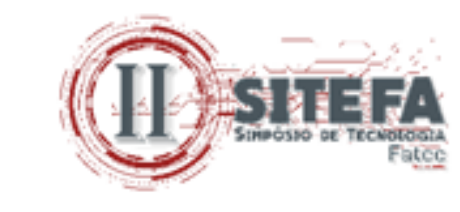

Fotografia 11 - Perfil da penetração da solda realizado à $100 \mathrm{~A}$ com eletrodo afiado à $15^{\circ}, 30^{\circ}$ e $45^{\circ}$, respectivamente, da esquerda para a direita

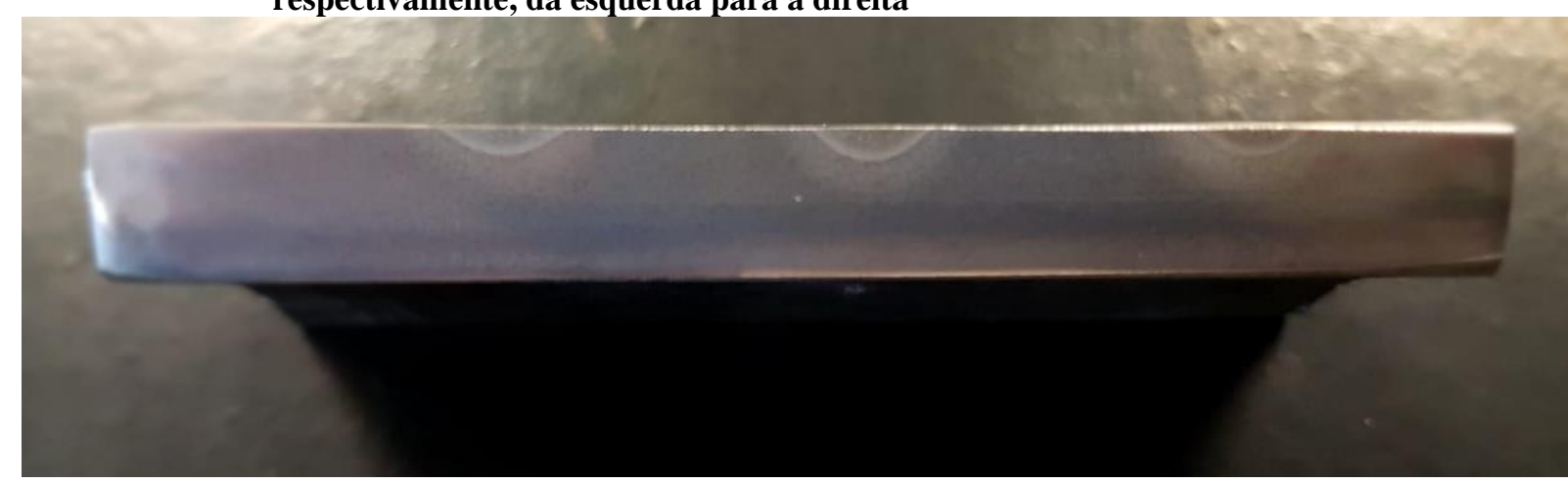

Fonte: fotografado pelos autores (2019)

As Fotografias 12 e 13 mostram o perfil dos cordões de solda executados com 120 e 160 A, respectivamente. Observa-se a mesma situação levantada anteriormente. A penetração obtida na soldagem com ângulo mais agudo $\left(15^{\circ}\right)$ é menor que a obtida nos ângulos de $45^{\circ} \mathrm{e}$ $30^{\circ}$, considerando o mesmo valor para todos os outros parâmetros. Sendo que, a partir do ângulo de $30^{\circ}$, o aumento do ângulo de afiação aumentou a penetração somente na soldagem com corrente de 160 A, conforme dados do Quadro 3.

Fotografia 12 - Perfil da penetração da solda realizado à $120 \mathrm{~A}$ com eletrodo afiado à $15^{\circ}, 30^{\circ}$ e $45^{\circ}$, respectivamente, da esquerda para a direita

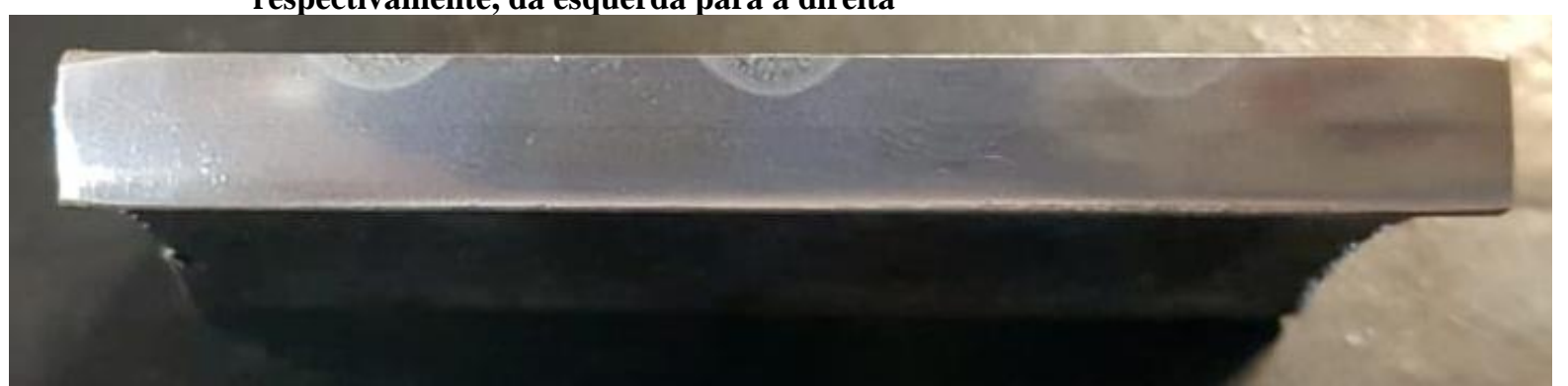

Fonte: fotografado pelos autores (2019)

Fotografia 13 - Perfil da penetração da solda realizado à $160 \mathrm{~A}$ com eletrodo afiado à $45^{\circ}, 30^{\circ}$ e $15^{\circ}$, respectivamente, da esquerda para a direita

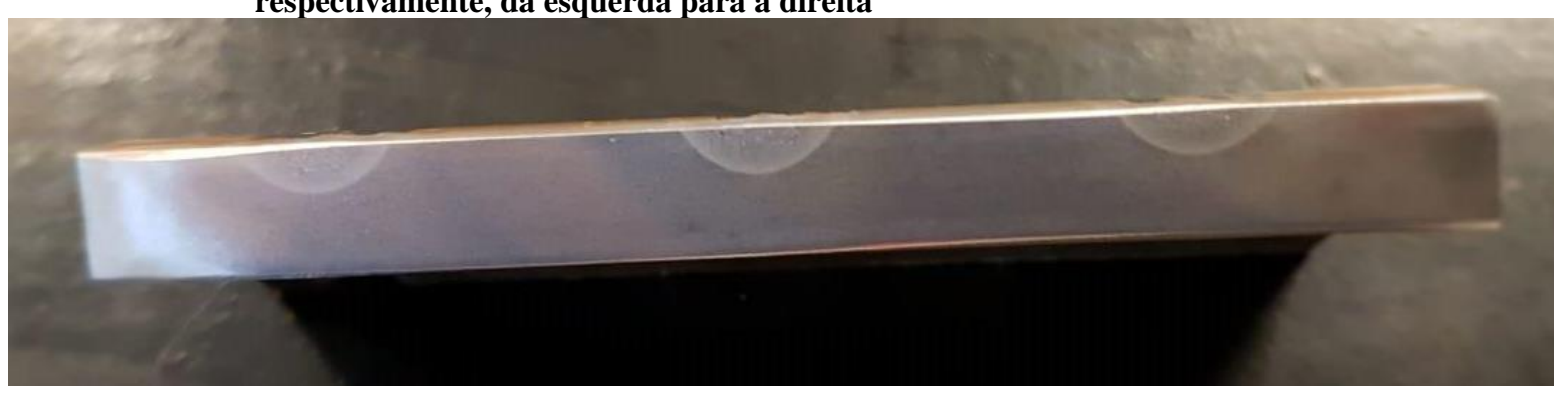

Fonte: fotografado pelos autores (2019) 
Quadro 3: Profundidade de penetração da solda em função do ângulo de afiação do eletrodo

\begin{tabular}{|c|c|c|}
\hline Corrente $(\mathrm{A})$ & Ângulo do vértice $\left.\mathbf{(}^{\mathbf{0}}\right)$ & Penetração da solda $(\mathrm{mm})$ \\
\hline \multirow{3}{*}{100} & 15 & 0,661 \\
\cline { 2 - 3 } & 30 & 0,979 \\
\cline { 2 - 3 } & 45 & 0,788 \\
\hline \multirow{3}{*}{120} & 15 & 1,095 \\
\cline { 2 - 3 } & 30 & 1,359 \\
\cline { 2 - 3 } & 45 & 1,315 \\
\hline \multirow{3}{*}{160} & 15 & 1,477 \\
\cline { 2 - 3 } & 30 & 1,544 \\
\cline { 2 - 3 } & 45 & 1,615 \\
\hline
\end{tabular}

Fonte: elaborado pelos autores (2019)

Baseado nos valores de penetração obtidos no Quadro 3, pode-se observar que:

- Em relação a corrente de 100 amperes, os eletrodos afiados à $30^{\circ}$ e $45^{\circ}$ geraram respectivamente cordões de solda com penetração $48 \%$ e $19 \%$ maiores que o eletrodo afiado à $15^{\circ}$.

- Em relação a corrente de 120 amperes, os eletrodos afiados à $30^{\circ}$ e $45^{\circ}$ geraram respectivamente cordões de solda com penetração $24 \%$ e $20 \%$ maiores que o eletrodo afiado à $15^{\circ}$.

- Em relação a corrente de 160 amperes, os eletrodos afiados à $30^{\circ}$ e $45^{\circ}$ geraram respectivamente cordões de solda com penetração $4 \%$ e $9 \%$ maiores que o eletrodo afiado à $15^{\circ}$.

Durante a soldagem, observou-se no eletrodo afiado à $15^{\circ}$, a formação de um segundo arco, aproximadamente no meio da ponta de afiação. Possivelmente a dissipação de energia causada por esse segundo arco diminui a energia no arco principal, afetando a penetração da solda. Nota-se, também, que tal fenômeno não ocorre durante a soldagem com eletrodos afiados à $30^{\circ}$ e $45^{\circ}$, justificando a maior penetração obtida nessas situações.

\section{CONSIDERAÇÕES FINAIS}

Com base nos resultados obtidos na análise da influência do ângulo de afiação do eletrodo de tungstênio na penetração da solda, considerando três valores de corrente e três ângulos de afiação do vértice, pode-se concluir que a influência da geometria da ponta do eletrodo, no processo de soldagem TIG, sobre a penetração da solda e a forma e tensão do arco é significativa, afetando consideravelmente as dimensões da solda.

Foi possível concluir, ainda, que a penetração da solda aumenta conforme aumenta-se o ângulo da ponta do eletrodo, atingindo seu maior valor no ângulo de $30^{\circ}$. A partir deste valor o aumento do angulo é insignificante na penetração, diminuindo-a, em alguns casos.

De acordo com o Serviço Nacional de Aprendizagem Industrial (2013) a afiação de duas vezes o diâmetro do eletrodo se mostra eficiente para obter a maior penetração para a corrente em uso. Considerando o eletrodo de $2,4 \mathrm{~mm}$, a afiação de duas vezes o diâmetro formará um cone com 4,8mm de comprimento. O mesmo eletrodo com uma afiação com ângulo de $30^{\circ}$ (ângulo com o qual se obteve a maior penetração) formará um cone com comprimento de $4,5 \mathrm{~mm}$. Ou seja, valores bastante próximos. 


\section{REFERÊNCIAS}

COLPAERT, Hubertus. Metalografia dos produtos siderúrgicos comuns. 3. ed. São Paulo: Edgard Blücher, 1983. 412 p.

GIL, Antônio Carlos. Como elaborar projetos de pesquisa. 4. ed. São Paulo: Atlas, 2002.

MARQUES, P.V., MODENESI, P.J, BRACARENSE, A.Q. SOLDAGEM. Fundamentos e Tecnologia. 3. ed. Belo Horizonte: UFMG, 2009.

MODENESI, Paulo J. Soldabilidade de algumas ligas metálicas. 2011. Disponível em: http://demet.eng.ufmg.br/wp-content/uploads/2012/10/soldabilidade.pdf. Acesso: 22 maio 2019.

A química da formação do cordão na soldagem TIG. Soldag. insp., São Paulo, v. 18, n. 3, p. 287-300, set. 2013. Disponível em: http://www.scielo.br/pdf/si/v18n3/11.pdf. Acesso em: 03 maio 2019.

PAVANATI, Henrique Cezar. Noções básicas de preparação metalográfica. 2019.

Disponível em: http://pavanati.com.br/doc/Teoria\%20Basica\%20de\%20Metalografia.pdf. Acesso em: 20 abr. 2019.

SERVIÇO NACIONAL DE APRENDIZAGEM INDUSTRIAL. Departamento Regional de São Paulo. Soldagem. São Paulo: SENAI-SP Editora, 2013. 719 p. 